\title{
Pneumoscrotum after colonoscopy
}

\author{
Sandeep Singh MD, Manika Thakur MD
}

\begin{abstract}
S Singh, M Thakur. Pneumoscrotum after colonoscopy. Can J Gastroenterol 2008;22(4):411-413.

Pneumoscrotum is an unusual problem that is very rarely associated with gastrointestinal endoscopy procedures. It has been reported to occur after colonoscopy and polypectomy. The present paper describes the case of an 81-year-old man with benign pneumoscrotum that formed after polypectomy at the site of a previous rectal polyp. The pneumoscrotum was managed with conservative treatment.
\end{abstract}

\section{Un pneumoscrotum après une coloscopie}

Le pneumoscrotum est un problème inhabituel très rarement associé à une endoscopie gastro-intestinale. On a déclaré des cas après une coloscopie et une polypectomie. Le présent article décrit le cas d'un homme de 81 ans atteint d'un pneumoscrotum bénin qui s'est formé après une polypectomie au foyer d'un ancien polype rectal. Le pneumoscrotum a été pris en charge au moyen d'un traitement classique.

Key Words: Colonoscopy; Perforation; Scrotum

\section{CASE PRESENTATION}

An 81-year-old man underwent a screening colonoscopy one year before presentation. His pertinent medical history was significant for a seven-year history of chronic lymphocytic leukemia (CLL), which did not require any treatment. On examination, he had a $4 \mathrm{~cm}$ villous-appearing sessile polyp of the distal rectum (Figure 1). The polyp was excised by standard polypectomy (Figure 2) using electrocautery, and there were no immediate or delayed postpolypectomy complications. The pathology of the polyp was that of a villous adenoma. Given the size and histology of the polyp, it was believed to be appropriate to verify by follow-up examination that there was no residual polyp. The patient remained clinically asymptomatic in the interim and then presented for a flexible sigmoidoscopy one year after the index examination. The flexible sigmoidoscopy showed a residual polypoid area of approximately $5 \mathrm{~mm}$ in size, at the site of the previous polypectomy. The polyp was reexcised using a snare with electrocautery. The patient was discharged home without any immediate problems. Approximately $6 \mathrm{~h}$ after discharge, the patient complained of swelling around the scrotum and his penis. He then presented for further evaluation. An initial examination determined that the patient's vital signs were stable. The abdomen was benign, with normoactive bowel sounds and no abdominal tenderness. Examination of the genitalia showed accumulation of air around the shaft of the penis and around the scrotum (Figure 3). A computed axial tomography scan confirmed the presence of pneumoperitoneum, with air around the penis, in the scrotum (Figure 4) and in the retroperitoneum (Figure 5). The laboratory data showed a white blood cell count of $35 \times 10^{9} / \mathrm{L}$, which was his baseline level due to CLL, and normal liver function tests. The patient was kept nil per os overnight. He was closely examined clinically in the first $48 \mathrm{~h}$. His pneumoscrotum showed clinical stability. After $48 \mathrm{~h}$, the patient was started on a full liquid diet and then advanced to a regular diet within $12 \mathrm{~h}$. The patient's white blood cell count remained stable at

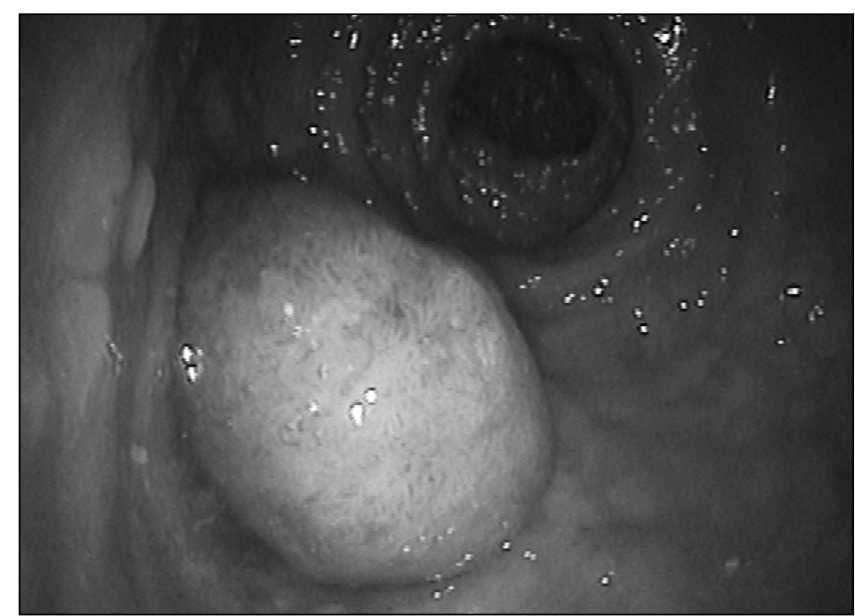

Figure 1) A $4 \mathrm{~cm}$ villous-appearing sessile polyp of the distal rectum

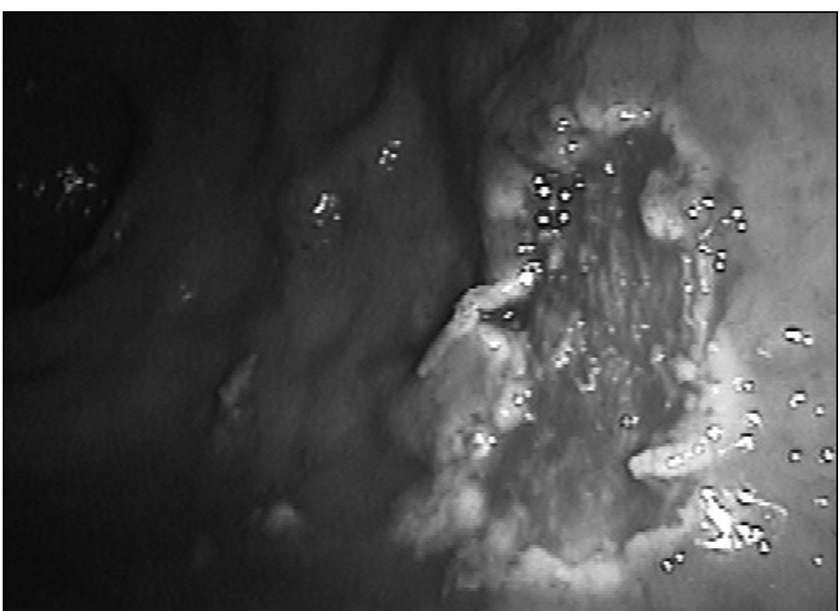

Figure 2) The distal rectum after the polyp shown in Figure 1 was excised by standard polypectomy using electrocautery

Eastern Maine Medical Center, Bangor, Maine, USA

Correspondence: Dr Sandeep Singh, Eastern Maine Medical Center, 489 State Street, Bangor, Maine 04401, USA. Telephone 207-947-6116, fax 207-990-1861, e-mail ssingh21@yahoo.com

Received for publication October 21, 2007. Accepted November 19, 2007 


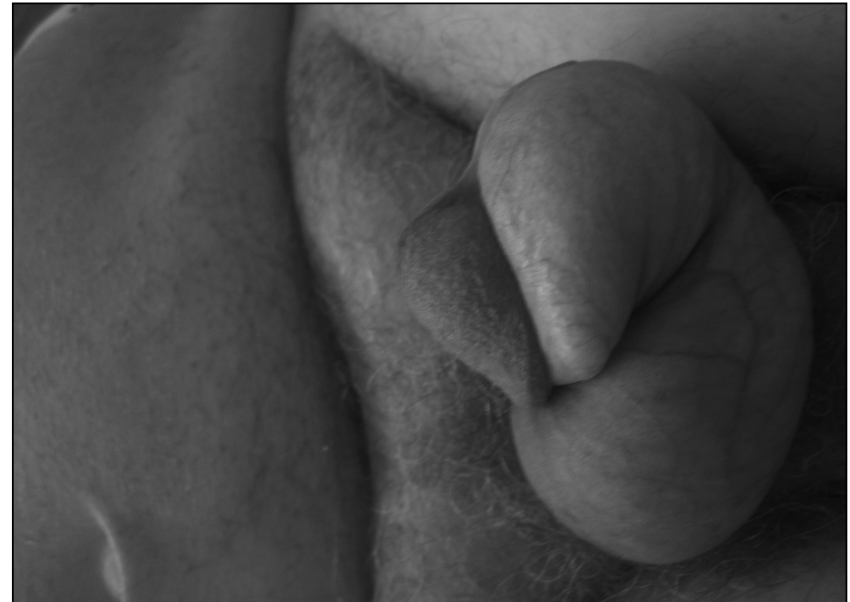

Figure 3) The patient's genitalia, showing accumulation of air around the shaft of the penis and in the scrotum

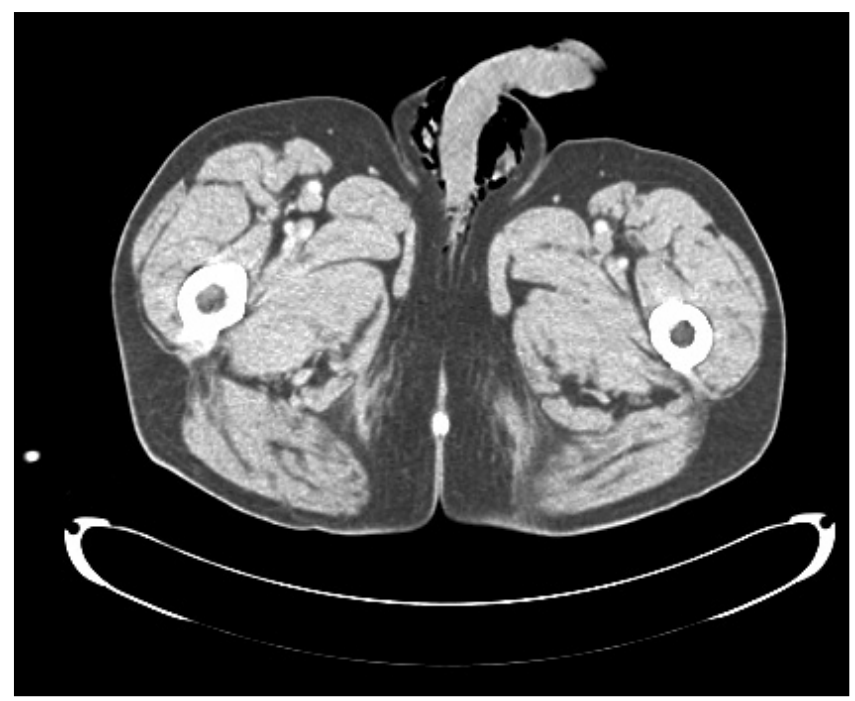

Figure 4) Computed axial tomography scan of the patient's genitalia, with air around the penis and in the scrotum

$35 \times 10^{9} / \mathrm{L}$. He continued to urinate without any assistance of a Foley catheter. He was discharged home after two days of hospitalization. A follow-up examination two weeks later showed complete resolution of the pneumoscrotum. Although the patient had CLL, he did not require any antibiotic treatment. The pathology from the residual polypoid area showed prolapsed rectal mucosa tissue with no adenoma. No muscle layer or submucosa was identified on the resected specimen.

\section{DISCUSSION}

Colonoscopy is considered to be safe, with a low incidence of complications (1). Postcolonoscopy perforations are rare, with both intra- and retroperitoneal cases being described. Pneumoscrotum refers to the presence of air in the scrotum. There are three ways to explain the phenomenon of pneumoscrotum: subcutaneous or retroperitoneal air that dissects into the dartos lining of the scrotal wall, local gas production or air introduction, and movement of air from the intraperitoneal space into the scrotum. Local air production usually suggests serious pathology, such as gas gangrene, requiring urgent surgical interventions (2). The literature shows only six cases of

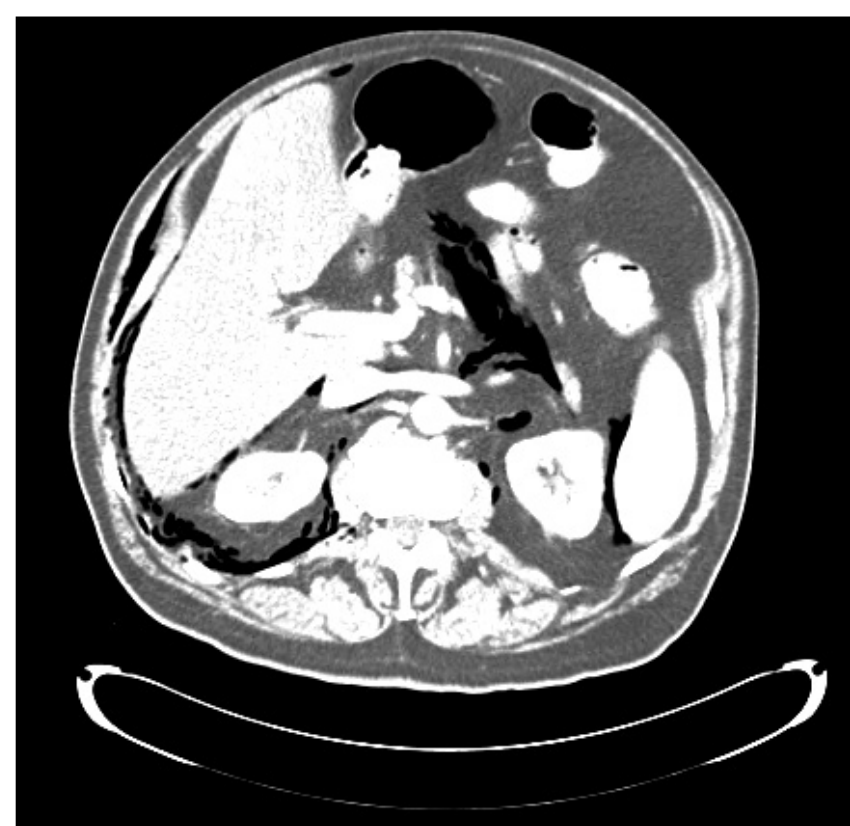

Figure 5) Computed axial tomography scan of the patient's genitalia, which confirmed the presence of air in the retroperitoneum

pneumoscrotum after colonoscopy (3-8). All were associated with pneumoperitoneum due to retroperitoneal perforation with or without intraperitoneal air leakage. One of these patients (7) had an endoscopic mucosal resection of an adenoma with intramucosal carcinoma by argon plasma coagulation. The onset time of pneumoscrotum after colonoscopy has been variable, with both early (arbitrarily defined as within $1 \mathrm{~h}$ after the procedure) and late onset (more than $6 \mathrm{~h}$ after the procedure) being described. One of these patients (8) did require surgical exploration, but no signs of perforation were found during laparotomy, and no definitive surgical repair was needed. Air from colonoscopy can also find its way into the mediastinum and the neck, particularly when scoping a rectal stump.

The management of these reported patients with pneumoscrotum usually has been nonsurgical. All nonsurgical patients received antibiotics with complete resolution. Graepler et al (8) describe one patient in whom laparotomy was performed. The patient underwent a colonoscopy and a polypectomy, with clipping of the postpolypectomy site, because the mucosal defect was believed to be deep. The patient developed swelling of his scrotum $30 \mathrm{~min}$ after the exam, which increased over the next few hours, prompting surgical exploration. Interestingly and fortunately, no perforation was identified and no primary repair was undertaken.

In our case, no perforation was identified during the operation, and the mucosal defect was not deep. A microperforation was not entirely ruled out, but the most likely explanation is that air was translocated through the mucosal defect into the retroperitoneum and then across the dartos muscle into the scrotum. Nonsurgical treatment was chosen because of the delayed presentation, lack of abdominal and perineal pain, and clinical stability. Despite the fact that the patient had CLL, which is a potentially immuno-compromising disease state, antibiotics were not required. Our case, which is the seventh reported in the literature, illustrates again the favourable outcome in this clinical scenario. 


\section{SUMMARY}

Pneumoscrotum is a very unusual complication of colonoscopy and, as a general rule, has a benign outcome. In the absence of any signs to suggest intraperitoneal inflammation, the choice of treatment should be close clinical observation, with judicious use of antibiotics and serial monitoring of the patient.

\section{REFERENCES}

1. Silvis SE, Nebel O, Rogers G, Sugawa C, Mandelstam P. Endoscopic complications: Results of 1974 American Society for Gastrointestinal Endoscopy Survey. JAMA 1976;235:928-30.

2. Watson HS, Klugo RG, Coffield KS. Pneumoscrotum: Report of two cases and review of mechanisms of its development. Urology 1992;40:517-21.
3. Fishman EK, Goldman SM. Pneumoscrotum after colonoscopy. Urology 1981;18:171-2.

4. Humphreys F, Hewetson KA, Dellipiani AW. Massive subcutaneous emphysema following colonoscopy. Endoscopy 1984;16:160-1.

5. Carlsen CU, Andreassen KH. [Benign pneumoperitoneum and scrotal emphysema after colonoscopy.] Ugeskr Laeger 1992;154:1785-6.

6. Goerg KJ, Duber C. [Retroperitoneal, mediastinal and subcutaneous emphysema with pneumothorax after colonoscopy.] Dtsch Med Wochenschr 1996; 121:693-6

7. Fu KI, Sano Y, Kato S, et al. Pneumoscrotum: A rare manifestation of perforation associated with therapeutic colonoscopy. World J Gastroenterol 2005;11:5061-3.

8. Graepler R, Lauer UM, Horger MS, Ladurner R, Gregor M. Pneumoscrotum after colonoscopic polypectomy. Endoscopy 2007;39:E90 
Singh and Thakur 


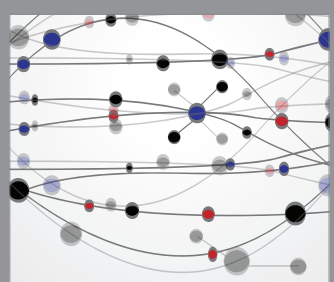

The Scientific World Journal
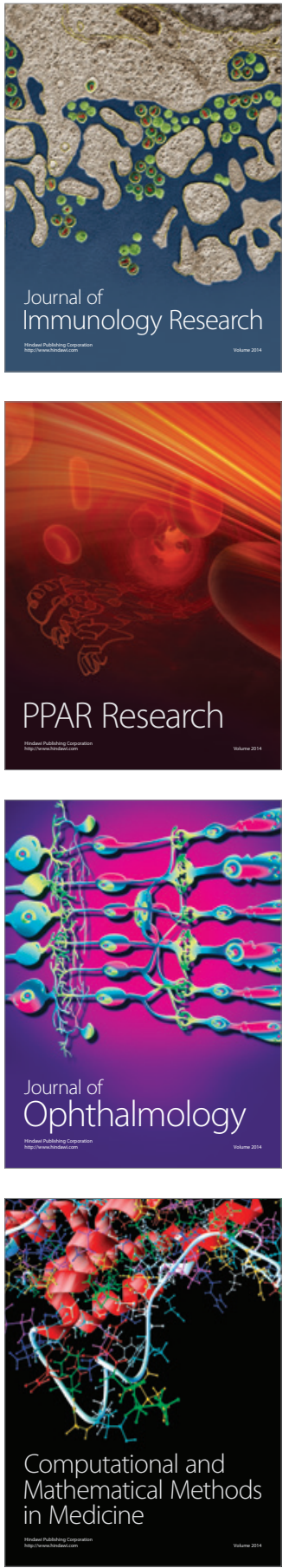

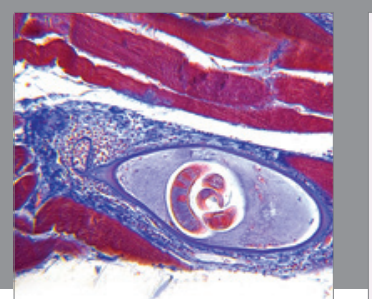

Gastroenterology Research and Practice

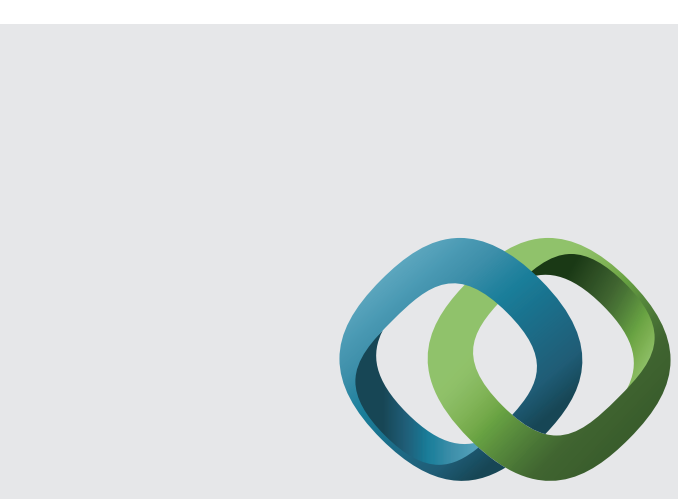

\section{Hindawi}

Submit your manuscripts at

http://www.hindawi.com
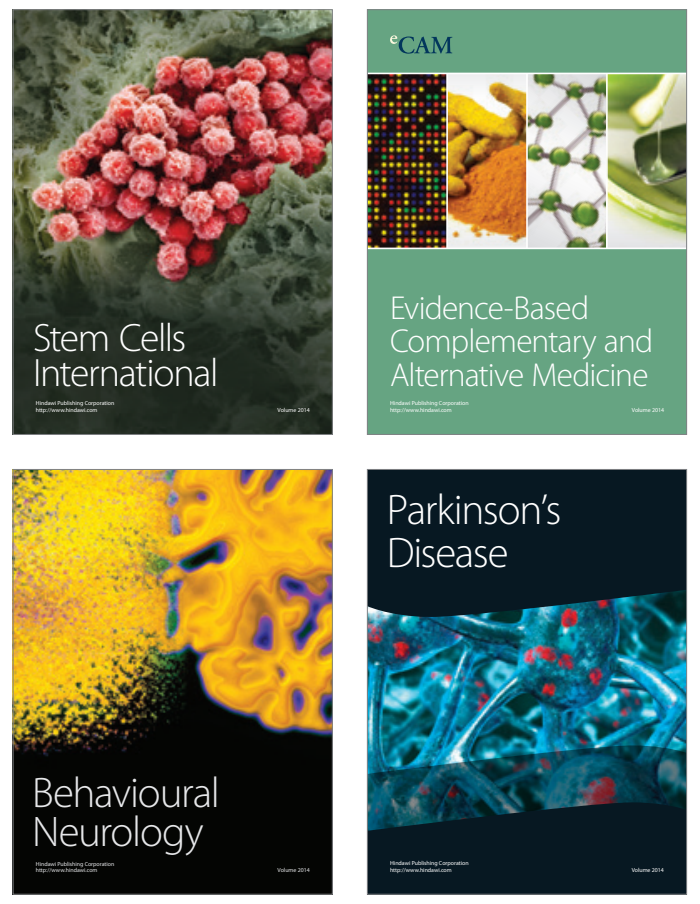
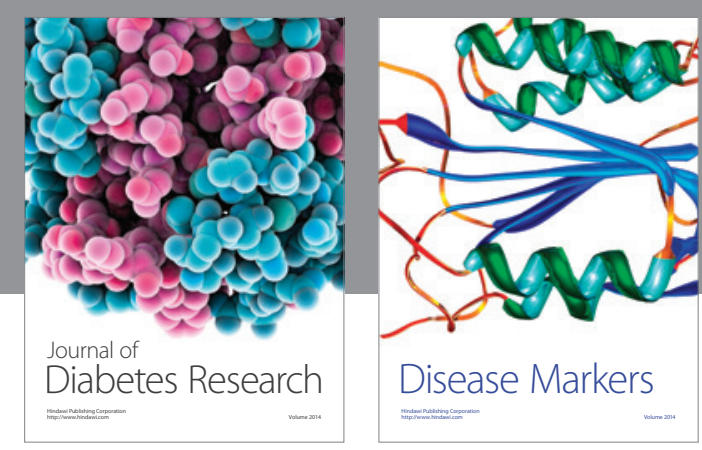

Disease Markers
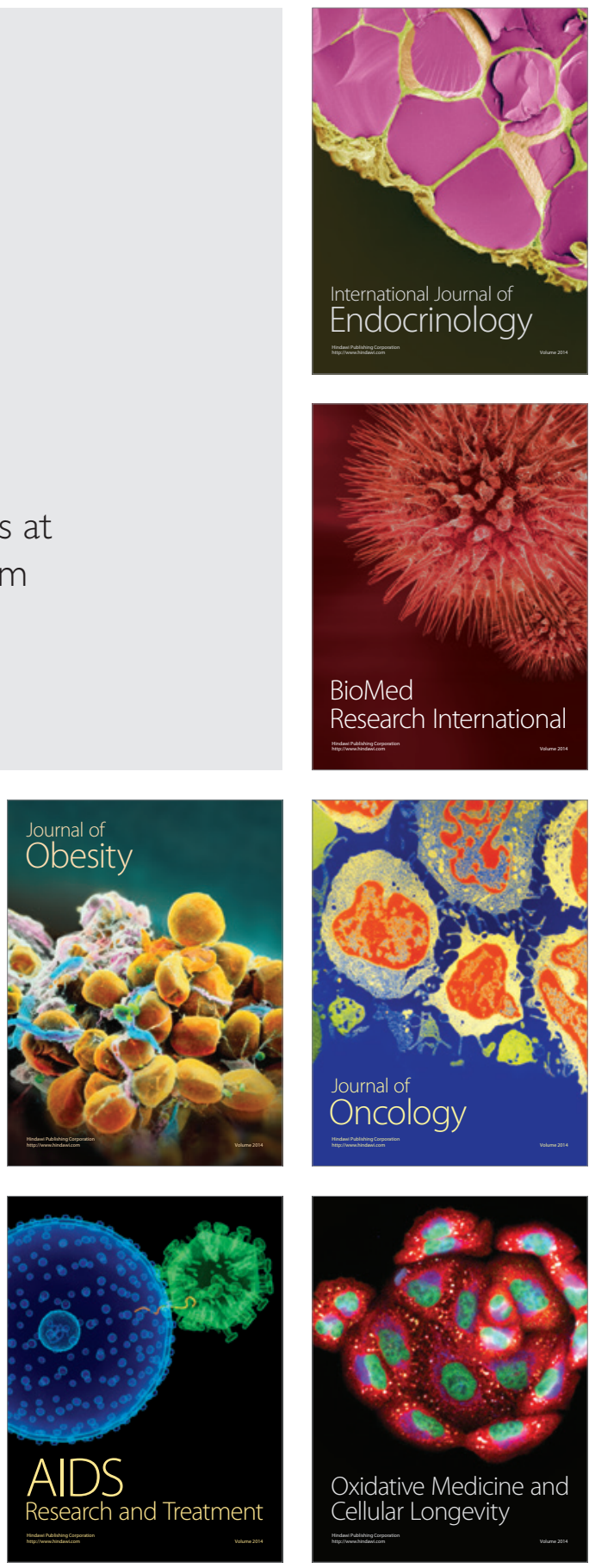